\title{
BMJ Open Impact of smoking on fertility and age of menopause: a population-based assessment
}

\author{
Jean-Baptiste Oboni, Pedro Marques-Vidal, François Bastardot, Peter Vollenweider, \\ Gérard Waeber
}

To cite: Oboni J-B, MarquesVidal $P$, Bastardot $F$, et al. Impact of smoking on fertility and age of menopause: a population-based assessment. BMJ Open 2016;6:e012015. doi:10.1136/bmjopen-2016012015

- Prepublication history and additional material is available. To view please visit the journal (http://dx.doi.org/ 10.1136/bmjopen-2016012015).

Received 23 March 2016 Revised 10 August 2016 Accepted 23 August 2016

CrossMark

Department of Internal Medicine, Lausanne University Hospital (CHUV), Lausanne, Switzerland

Correspondence to Dr Gerard Waeber; Gerard.Waeber@chuv.ch

\section{ABSTRACT}

Background and aims: Studies in patients seeking medically assisted reproduction have shown that smoking reduces fertility, but little information is available in the general population. We assessed the associations between smoking and the number of children, childbearing planning and age at menopause in a representative sample of the population of Lausanne, Switzerland.

Methods: Data from 6711 participants (3530 women, age range 35-75 years) collected between 2003 and 2006 and again in 2009 and 2012. Smoking status, number of offsprings and age of menopause were assessed.

Results: Women who currently smoke had significantly less children than former or never smokers: the number of children per women (average $\pm S D$ ) was $1.38 \pm 1.05,1.45 \pm 1.07$ and $1.576 \pm 1.16$, respectively $(p<0.001)$. Women who currently smoke had their first child at an earlier age than the others: $26.7 \pm 5.2,27.4 \pm 5.4$ and $26.9 \pm 5.2$ years old for current, former and never smokers, respectively, $(p=0.01)$. Similar findings were found for men: number of children per men $1.475 \pm 1.16,1.67 \pm 1.13$ and 1.55 \pm 1.22 for current, former and never smokers, respectively $(p<0.001)$; no difference was found regarding age at the first child. The difference persisted after multivariate adjustment (adjusted for age, body mass index, Caucasian origins, alcohol consumption, caffeinated drinks consumption, educational level, receiving social help and women taking contraceptives) for the age at first child among women. No association was found between Heaviness of Smoking Index and the number of children among current smokers in both genders. Women who smoke had their menopause more than 1 year prior than never-smoking women $(48.9 \pm 0.2$ years compared with $47.8 \pm 0.3$ years,

respectively, $p=0.002$ ).

Conclusions: Smoking is associated with an earlier age of having the first child and of menopause among women.

\section{INTRODUCTION}

Smoking has been cited as a cause of infertility in both genders, ${ }^{12}$ but the mechanisms

\section{Strengths and limitations of this study}

- The study collected data on large number of participants, representative sample of the population of Lausanne, Switzerland.

- Adjustment for a number of possible confounding variables known to influence fertility such as alcohol and caffeine intake, certain drugs or body mass index.

- No data was available regarding the number of pack-years smoked, information on secondhand smoke, the smoking status of the parents and time after quitting for former smokers.

- No data was collected regarding the willingness to have children or the number of pregnancies (including stillborn, voluntary abortions or miscarriages).

by which smoking leads to infertility are not clearly understood. Most studies on smoking and infertility were conducted in the setting of medically assisted procreation. ${ }^{3}$ A meta-analysis conducted in the late nineties showed an OR of 1.60 (95\% CI 1.34 to 1.91 ) for infertility among female smokers compared with non-smokers. ${ }^{4}$ The effect of smoking on female fertility appears to be dose dependant ${ }^{5}$ and even secondhand smoking has been shown to reduce the chance to give birth in an assisted reproduction programme. $^{6}$ Smoking during pregnancy could also decrease fertility of the future female about to be born. ${ }^{7}$ One of the first cohort studies to show the association between smoking and age at menopause was conducted in $1977 .^{8}$ More recently, two large cohort studies of over 50000 and 90000 women, respectively, have shown that smoking was associated with earlier menopause. $^{910}$

Moreover, in a recent meta-analysis, female smokers experienced menopause almost a year earlier than never smokers, and this difference was even greater in economically developed regions. ${ }^{11}$ For men, the literature 
is more limited. Smokers tend to have lower spermatozoid absolute count, density and motility, less semen volume and more abnormal morphology specimens than non-smokers. ${ }^{12-14}$ Interestingly, most studies on smoking and fertility were conducted among medically assisted procreation couples, and few data exist on the associations between smoking and fertility in the general population. The Avon Longitudinal Study of Pregnancy and Childhood (ALSPAC) reported a delayed conception time in smoking couples expecting a baby, or in future mothers exposed to passive smoke. ${ }^{15}$ The ALSPAC focused mainly on delayed conception and little data on the number of children was provided.

Hence, we used the data from a population-based survey conducted in Switzerland to assess the association between smoking status and Heaviness of Smoking Index (HSI) with the number of children, the age at first child, and the age at menopause.

\section{METHODS}

\section{Study population}

Data from participants of the CoLaus study were analysed. The CoLaus study is a large population-based cohort, aimed at assessing the determinants of cardiovascular disease in the population of Lausanne, Switzerland. All participants signed a written informed consent.

The sampling frame and methodology of the CoLaus study have been described elsewhere. ${ }^{16}$ The following inclusion criteria were applied: written informed consent; age $35-75$ years; willingness to take part in the examination and to donate a blood sample.

\section{Study procedures and measurements}

All participants were assessed in an outpatient clinic of the University Hospital of Lausanne. Data were collected by trained field interviewers during a single visit lasting about $60 \mathrm{~min}$. Information on demographic data, socioeconomic and marital status, lifestyle factors, personal and family history of disease, cardiovascular risk factors and treatment was collected. Recruitment began in June 2003 and ended in May 2006 and included 6184 Caucasian participants. The evaluation included an interview, a physical examination, blood sampling and a set of questionnaires. The follow-up was performed between April 2009 and September 2012, five and a half years on average after the collection of baseline data and was similar to the baseline evaluation. Further details regarding the baseline and the first follow-up can be found elsewhere. ${ }^{16}$ The time of examination was independent of the family planning schedule or other variables, as it was an instantaneous picture at this moment.

\section{Smoking habits}

Smoking habits were assessed by questionnaire and the participants were categorised in never, former and current smokers. Current smoking was defined if the participant reported smoking at the time of examination, irrespective of the amount of tobacco smoked. Participants were considered as former smokers if they reported to have smoked in the past but not anymore at the time of examination, irrespective of the date of quitting.

Participants who smoked were further invited to a substudy assessing smoking characteristics and asked about the amount of tobacco smoked daily. This was irrespective of the moment of their family life, meaning it could be before, during or after childbearing, depending of the participant. Cigar, cigarillo or pipes were converted into cigarette equivalents using the following criteria: 1 pipe or cigarillo $=2.5$ cigarettes and 1 cigar $=5$ cigarettes. ${ }^{17}$ The number of cigarette equivalents smoked per day was then used to compute the HSI. The HSI includes a score for the amount of tobacco smoked $(0$ for $0-10$; 1 for $11-20$; 2 for $21-30$ and 3 for $>31$ cigarette equivalents/day) and a score for the time to the first cigarette consumed after waking $(0$ for $>61 ; 1$ for 31-60; 2 for $6-30$ and 3 for $\leq 5 \mathrm{~min}) .{ }^{18}$ HSI values ranged from 0 to 6 and three HSI categories were made: low (scores $0-1$ ), medium (scores 2-4) and high (scores 5-6).

\section{Number of children and contraception}

The number of children and age of the participant at the first birth of her/his offspring was assessed as reported by the participants.

Contraception was defined as a positive answer to the question 'Do you currently take contraceptives '. Other information such as ever taken contraceptives (yes/no), age at start and end of contraceptive use, and duration of contraceptive use (in years) was also collected. When the participant reported currently using contraceptives, duration of use was calculated using the actual age of the participant. When the duration of contraceptive use was $<1$-year, the value of 0.5 was used.

\section{Age at menarche and at menopause}

Age at menarche was assessed by asking the women at which age they had their menses. Women were also asked if they had a hysterectomy coupled with ovariectomy, but the date of the intervention was not recorded.

Menopause was assessed by asking the women the age of cessation of menses, regardless of the cause of menopause (natural vs induced), and regardless of the use of hormonal replacement therapy.

\section{Other data}

Marital status was categorised into married/living together; divorced; single and widowed.

Socioeconomic status was categorised according to educational level, defined as the highest qualification achievement. Three categories were made: low (mandatory school), middle (secondary or postsecondary education such as apprenticeship) and high (university degree). Receiving social help (because of 
unemployment) was used as a second marker of socioeconomic status. Caucasian origin was defined as having all four grandparents living in a selected number of countries (list available from the authors on request).

Body weight and height were measured with participants standing without shoes in light indoor clothes. Body weight was measured in kilograms to the nearest $100 \mathrm{~g}$ using a Seca scale, which was calibrated regularly. Height was measured to the nearest $5 \mathrm{~mm}$ using a Seca height gauge. Overweight was defined as a body mass index $(\mathrm{BMI}) \geq 25$ and $<30 \mathrm{~kg} / \mathrm{m}^{2}$; obesity was defined as a $\mathrm{BMI} \geq 30 \mathrm{~kg} / \mathrm{m}^{2}$.

Venous blood samples were drawn after overnight fasting, and assays were performed by the Centre Hospitalier Universitaire Vaudois (CHUV) Clinical Laboratory on fresh plasma samples within 2-hour of blood collection in a Modular $\mathrm{P}$ apparatus (Roche Diagnostics, Switzerland). Diabetes was defined as fasting plasma glucose of $\geq 7 \mathrm{mmol} / \mathrm{L}$ and/or drug treatment for diabetes.

Alcohol consumption was assessed by asking the participants how many units (glasses, shots, cans) they had consumed during the previous 7 days. Participants were defined as non-drinkers, low (1-13 units/week), middle (14-27 units/week) and high ( $\geq 28$ units/week) drinkers.

Caffeine intake was assessed by asking the participants how many caffeinated drinks (including energy drinks) they consumed per day. Participants were defined as non-users, low (1-3 cups/day), middle (4-6 cups/day) and high ( $\geq 6$ cups/day) consumers.

Drug treatments were assessed by asking the participants to bring all their prescribed and non-prescribed drugs. Drugs known to influence fertility such as retinoic acid or anticancer drugs (any type) were identified.

\section{Statistical analysis}

Statistical analysis was conducted using Stata V.13.0 (Stata Corp, College Station, Texas, USA). The number of children and the age at first birth were analysed separately for each gender. Results were expressed as number of participants and (percentage) or as mean $\pm \mathrm{SD}$. Between-groups comparisons were performed using $\chi^{2}$ for qualitative data and Student's t-test or analysis of variance (ANOVA) for quantitative data. As the distribution of the number of children was skewed, comparisons were performed using nonparametric tests.

Multivariate analysis was conducted using ANOVA and the results were expressed as adjusted mean \pm SE. Two multivariate adjusted models were built: the first one was adjusted for age, BMI, Caucasian status (yes/no), alcohol consumption (four groups), caffeinated drinks consumption (four groups), educational level (three groups) and receiving social help (yes/no). These adjustment variables were characterising the population in more details, and assessing additional stress factors. The second one was adjusted similarly plus diabetes (yes/no), marital status (married/living together; divorced; single and widowed), contraception (for women), retinoic acid and anticancer drugs. These variables were chosen for their interaction with fertility, as described in the literature. ${ }^{2}$ Results were expressed as multivariate adjusted mean $\pm \mathrm{SE}$ and post-hoc bivariate comparisons were performed using the Scheffe's method. Sensitivity analyses were conducted by restricting the sample to women (1) without hysterectomy and (2) not taking contraceptives. Linear trends between dependent and categorical variables (ie, smoking or HSI categories) were assessed using the contrast $p$. function of Stata.

The impact of smoking on incidence of menopause was assessed by restricting the analyses to nonmenopausal women at baseline and assessing the age of cessation of menses. Only women with follow-up were included, so no censoring occurred; also, it was not possible assessing whether menopause was natural or surgically induced. Analysis was conducted using Cox proportional hazards regression and the results were expressed as multivariate adjusted HR and (95\% CI). The proportional hazards assumption was tested using the estat phtest command, uses Schoenfeld residuals; a significant test indicates deviation from the proportional hazards assumption. Statistical significance was assessed for two-sided tests with $\mathrm{p}<0.05$.

\section{RESULTS}

\section{Characteristics of the studied population}

Of the initial 6733 participants, $22 \quad(0.3 \%)$ were excluded because of missing data regarding smoking habits, BMI, education, caffeinated drinks consumption and the number of children. The characteristics of the remaining 6711 participants according to gender are summarised in table 1.

Women were older, with lower educational level, had a lower BMI and prevalence of diabetes than men. Women also reported lower alcohol consumption and being often on retinoic or anticancer drugs than men, while no differences were found regarding caffeinated drinks consumption or Caucasian origin.

Women were less frequently current or former smokers than men. Among current smokers, women had a lower HSI than men. Women reported a lower number of children and a lower age at first birth than men (table 1). Finally, 517 women (14.7\%) reported having had a hysterectomy with ovariectomy.

\section{Smoking and number of children, men}

The effect of smoking status and of HSI on the number of children and on the age at first birth among men is summarised in table 2.

On bivariate analysis, current smokers had a lower number of children than never smokers, but this difference was no longer significant after multivariate adjustment. No significant difference was found between 
Table 1 Characteristics of the sample, overall and by gender

\begin{tabular}{|c|c|c|c|c|}
\hline & All & Women & Men & p Value \\
\hline Sample size & 6711 & 3530 & 3181 & \\
\hline Caucasian & 6176 (92.0) & 3246 (92.0) & 2930 (92.1) & 0.815 \\
\hline Age (years) & $52.6 \pm 10.7$ & $53 \pm 10.7$ & $52.2 \pm 10.7$ & $2.30 \times 10^{-3}$ \\
\hline \multicolumn{5}{|l|}{ Smoking status } \\
\hline Never & 2723 (40.6) & $1681(47.6)$ & 1042 (32.8) & \multirow{3}{*}{$2.10 \times 10^{-35}$} \\
\hline Former & $2182(32.5)$ & $972(27.5)$ & $1210(38.0)$ & \\
\hline Current & 1806 (26.9) & 877 (24.8) & $929(29.2)$ & \\
\hline \multicolumn{5}{|l|}{ HSI categories* } \\
\hline Low (0-1) & 447 (35.6) & $230(38.6)$ & $214(32.8)$ & \multirow{3}{*}{0.001} \\
\hline Medium (2-4) & $642(51.1)$ & $312(51.7)$ & $330(50.5)$ & \\
\hline High (5-6) & $168(13.4)$ & $59(9.8)$ & 109 (16.7) & \\
\hline \multicolumn{5}{|l|}{ HSI categories* } \\
\hline 0 & $298(22.8)$ & 157 (25.2) & $141(20.6)$ & \multirow{7}{*}{0.016} \\
\hline 1 & $166(12.7)$ & $83(13.3)$ & $83(12.1)$ & \\
\hline 2 & $194(14.8)$ & $92(14.7)$ & $102(14.9)$ & \\
\hline 3 & 277 (21.2) & $136(21.8)$ & 141 (20.6) & \\
\hline 4 & 193 (14.7) & $93(14.9)$ & $100(14.6)$ & \\
\hline 5 & $113(8.6)$ & $39(6.3)$ & $74(10.8)$ & \\
\hline 6 & $68(5.2)$ & 24 (3.9) & $44(6.4)$ & \\
\hline \multicolumn{5}{|l|}{ Educational level } \\
\hline High & 1319 (19.7) & $571(16.2)$ & 748 (23.5) & \multirow{3}{*}{$4.00 \times 10^{-13}$} \\
\hline Middle & 1624 (24.2) & 894 (25.3) & 730 (23.0) & \\
\hline Low & 3768 (56.2) & 2065 (58.5) & $1703(53.5)$ & \\
\hline BMI $\left(\mathrm{kg} / \mathrm{m}^{2}\right)$ & $25.8 \pm 4.5$ & $25.1 \pm 4.8$ & $26.6 \pm 4.0$ & $5.70 \times 10^{-40}$ \\
\hline \multicolumn{5}{|l|}{ BMI categories } \\
\hline Normal & 3232 (48.2) & 2029 (57.5) & $1203(37.8)$ & \multirow{3}{*}{$3.11 \times 10^{-61}$} \\
\hline Overweight & 2451 (36.5) & $998(28.3)$ & $1453(45.7)$ & \\
\hline Obese & 1028 (15.3) & $503(14.3)$ & $525(16.5)$ & \\
\hline \multicolumn{5}{|l|}{ Alcohol consumption } \\
\hline Non-drinkers & 1897 (28.3) & 1347 (38.2) & $550(17.3)$ & \multirow{4}{*}{$7.77 \times 10^{-162}$} \\
\hline $1-13$ units/week & $3649(54.4)$ & $1942(55.0)$ & $1707(53.7)$ & \\
\hline 14-27 units/week & $913(13.6)$ & $215(6.1)$ & $698(21.9)$ & \\
\hline $28+$ units/week & $252(3.8)$ & $26(0.7)$ & $226(7.1)$ & \\
\hline \multicolumn{5}{|l|}{ Marital status } \\
\hline Married & 3974 (59.2) & $1833(51.9)$ & $2141(67.3)$ & \multirow{4}{*}{$2.32 \times 10^{-54}$} \\
\hline Divorced & 1355 (20.2) & $831(23.6)$ & $524(16.5)$ & \\
\hline Single & $1082(16.1)$ & $606(17.2)$ & $476(15.0)$ & \\
\hline Widowed & $299(4.5)$ & $259(7.3)$ & $40(1.3)$ & \\
\hline \multicolumn{5}{|l|}{ Caffeinated drinks } \\
\hline None & $449(6.7)$ & $241(6.8)$ & $208(6.5)$ & \multirow{4}{*}{0.198} \\
\hline 1-3/day & $4376(65.2)$ & $2324(65.8)$ & $2052(64.5)$ & \\
\hline 4-6/day & $1568(23.4)$ & $815(23.1)$ & $753(23.7)$ & \\
\hline $7+/$ day & $318(4.7)$ & $150(4.3)$ & $168(5.3)$ & \\
\hline Diabetes & $435(6.5)$ & $141(4.0)$ & $294(9.2)$ & $2.80 \times 10^{-18}$ \\
\hline \multicolumn{5}{|l|}{ Treatments } \\
\hline Retinoic acid & $26(0.4)$ & $20(0.6)$ & $6(0.2)$ & 0.013 \\
\hline Anticancer drugs & $84(1.3)$ & $63(1.8)$ & $21(0.7)$ & $3.51 \times 10^{-5}$ \\
\hline Number of children & $1.53 \pm 1.14$ & $1.50 \pm 1.11$ & $1.57 \pm 1.17$ & 0.005 \\
\hline Age at first birth $†$ & $28.2 \pm 5.5$ & $27.0 \pm 5.2$ & $29.6 \pm 5.5$ & $2.92 \times 10^{-65}$ \\
\hline
\end{tabular}

smoking status or HSI categories regarding age at first birth. HSI was negatively correlated with age at first birth (Spearman $\mathrm{r}=-0.122, \mathrm{p}<0.01$ ) but not with the total number of children $(\mathrm{r}=-0.042, \mathrm{p}=0.27)$.
Smoking and number of children, women

The effect of smoking status and of HSI on the number of children and on the age at first birth among women is summarised in table 3 . 
Table 2 Number of children and age at first birth according to smoking status, men

\begin{tabular}{|c|c|c|c|}
\hline & Model 1 & Model 2 & Model 3 \\
\hline \multicolumn{4}{|l|}{ Number of children } \\
\hline \multicolumn{4}{|l|}{ Smoking status } \\
\hline Never $(n=1042)$ & $1.55 \pm 1.22^{*}$ & $1.56 \pm 0.04$ & $1.56 \pm 0.03$ \\
\hline Former $(n=1210)$ & $1.67 \pm 1.13 \dagger$ & $1.63 \pm 0.03$ & $1.59 \pm 0.03$ \\
\hline Current $(n=929)$ & $1.47 \pm 1.16^{*}$ & $1.52 \pm 0.04$ & $1.57 \pm 0.03$ \\
\hline p Value & $2.72 \times 10^{-4}$ & 0.100 & 0.807 \\
\hline \multicolumn{4}{|l|}{ HSI categories $\ddagger$} \\
\hline Low $(n=214)$ & $1.50 \pm 1.14$ & $1.48 \pm 0.08$ & $1.43 \pm 0.07$ \\
\hline Medium $(n=330)$ & $1.37 \pm 1.18$ & $1.37 \pm 0.06$ & $1.41 \pm 0.05$ \\
\hline High $(n=109)$ & $1.29 \pm 1.09$ & $1.31 \pm 0.11$ & $1.32 \pm 0.10$ \\
\hline p Value & 0.257 & 0.412 & 0.682 \\
\hline \multicolumn{4}{|l|}{ Age at first birth } \\
\hline \multicolumn{4}{|l|}{ Smoking status } \\
\hline Never $(n=764)$ & $30.2 \pm 5.3$ & $29.9 \pm 0.2$ & $29.9 \pm 0.2$ \\
\hline Former $(n=979)$ & $29.4 \pm 5.7$ & $29.6 \pm 0.2$ & $29.6 \pm 0.2$ \\
\hline Current $(n=676)$ & $29.2 \pm 5.5$ & $29.3 \pm 0.2$ & $29.3 \pm 0.2$ \\
\hline p Value & $1.14 \times 10^{-3}$ & 0.119 & 0.155 \\
\hline \multicolumn{4}{|l|}{ HSI categories $\ddagger$} \\
\hline Low $(n=157)$ & $29.6 \pm 5.4$ & $29.4 \pm 0.5$ & $29.4 \pm 0.5$ \\
\hline Medium (n=225) & $28.9 \pm 5.7$ & $29.0 \pm 0.4$ & $29.0 \pm 0.4$ \\
\hline High $(n=76)$ & $28.3 \pm 5.6$ & $28.4 \pm 0.7$ & $28.4 \pm 0.7$ \\
\hline p Value & 0.252 & 0.431 & 0.487 \\
\hline
\end{tabular}

Results are expressed as mean \pm SD or as adjusted mean \pm SE. Between groups comparisons by analysis of variance. Model 1 , unadjusted; model 2, adjusted for age, body mass index,

Caucasian status (yes/no), alcohol consumption (four groups), caffeinated drinks consumption (four groups), educational level (three groups) and receiving social help (yes/no); model 3, same as model 2 plus diabetes (yes/no), marital status, retinoic acid and anticancer drugs. Post-hoc bivariate analyses by Scheffe's method; Groups with different superscript signs “* and †' are significantly different at $\mathrm{p}<0.05$.

$\ddagger$ : among 1257 current smokers.

HSI, Heaviness of Smoking Index.

On bivariate analysis, current smokers had a lower number of children than never smokers, and this difference persisted only after multivariate adjustment for age, BMI, Caucasian status, alcohol consumption, caffeinated drinks consumption, educational level and receiving social help (see model 2 in table 3). There was no statistically significant difference when adjusting in addition for diabetes, current contraception, marital status, retinoic acid and anticancer drugs (see model 3 in table 3 ), and with ever used contraception (see model 4 in table 3). Among current smokers, no association was found between HSI and the number of children (Spearman $\mathrm{r}=-0.007, \mathrm{p}=0.87$ ); similarly, no difference was found between HSI categories regarding the number of children (table 3 ).

Current smokers reported a lower age at first birth than former smokers, and this difference persisted after multivariate adjustment. Among current smokers, HSI was negatively correlated with age at first birth (Spearman $\mathrm{r}=-0.146, \mathrm{p}<0.005)$, and women in the highest HSI category reported a lower age at first birth than women in the low and medium categories (table 2). Further adjustment on ever taken contraception (yes/no) did not change the results (see model 4 in table 3 ).

Restricting the analysis to women without hysterectomy showed a similar albeit non-significant difference after multivariate adjustment: current smokers tended to have fewer children than never smokers ( $p$ value for trend $=0.035$, see online supplementary table $\mathrm{S} 1$ ). Restricting the analysis to women not taking contraceptives showed no association between smoking status and the number of children, but lower age at first birth among current smokers compared with never smokers (see online supplementary table S2). Further, a dosedependent inverse association was found between HSI categories and age at first birth (see online supplementary table S2). A negative correlation between individual HSI values and age at first birth was also found (Spearman $\mathrm{r}=-0.160, \mathrm{p}=0.0007$ ).

Smokers reported a younger age at start of contraception: multivariate adjusted mean \pm SE: $21.6 \pm 0.2,22.0 \pm 0.2$ and 23.6 \pm 0.1 years for current, former and never smokers, respectively, $\mathrm{p}<0.001$. Similar findings were observed for age at ending of contraception: multivariate adjusted mean \pm SE: $32.8 \pm 0.3, \quad 33.3 \pm 0.3$ and 34.1 \pm 0.3 years for current, former and never smokers, respectively, $\mathrm{p}<0.01$. Conversely, no differences were found regarding duration of contraceptive use: multivariate adjusted mean \pm SE: $11.7 \pm 0.3,12.0 \pm 0.3$ and 11.8 \pm 0.3 years for current, former and never smokers, respectively, $\mathrm{p}=0.82$. Finally, current and former smokers reported more frequently the use of contraceptives than never smokers: multivariate adjusted OR and 95\% CI 1.29 (1.04 to 1.61 ) and 1.75 (1.42 to 2.15) for current and former smokers, respectively, both $\mathrm{p}<0.05$.

\section{Smoking and age at menarche/menopause}

Age at menarche was not different according to smoking status: adjusted mean \pm SE: $13.3 \pm 0.04,13.2 \pm 0.05$ and 13.2 \pm 0.06 years for never, former and current smokers, respectively $(\mathrm{p}=0.129)$, and restricting the analysis to women without hysterectomy led to similar findings: adjusted mean \pm SE: $13.3 \pm 0.1,13.2 \pm 0.1$ and $13.3 \pm 0.1$ years for never, former and current smokers, respectively $(\mathrm{p}=0.218)$. Also, no difference was found between HSI categories (data not shown).

Age at menopause was assessed among 1903 women. Age at menopause was lower among current smokers than among never smokers and pairwise comparisons showed a significant difference between current and never smokers while no difference was found between former smokers and the other two groups (see online supplementary table S2). Conversely, age at menopause did not differ between HSI categories (see online supplementary table S3). Restricting the analysis to women without hysterectomy led to comparable findings, although the difference between smoking status was no longer significant $(\mathrm{p}=0.058$, see online supplementary table S3); conversely, an association 
Table 3 Number of children and age at first birth according to smoking status, women

\begin{tabular}{|c|c|c|c|c|}
\hline & Model 1 & Model 2 & Model 3 & Model 4 \\
\hline \multicolumn{5}{|l|}{ Number of children } \\
\hline \multicolumn{5}{|l|}{ Smoking status } \\
\hline Never $(n=1681)$ & $1.57 \pm 1.16^{*}$ & $1.56 \pm 0.03^{*}$ & $1.53 \pm 0.02$ & $1.53 \pm 0.02$ \\
\hline Former $(n=972)$ & $1.45 \pm 1.07 \dagger$ & $1.47 \pm 0.04^{\star} \dagger$ & $1.48 \pm 0.03$ & $1.48 \pm 0.03$ \\
\hline Current $(n=877)$ & $1.38 \pm 1.05 \dagger$ & $1.41 \pm 0.04 \dagger$ & $1.45 \pm 0.03$ & $1.46 \pm 0.03$ \\
\hline $\mathrm{p}$ Value & $3.79 \times 10^{-5}$ & 0.009 & 0.118 & 0.171 \\
\hline \multicolumn{5}{|l|}{ HSI categories } \\
\hline Low $(n=233)$ & $1.42 \pm 1.00$ & $1.46 \pm 0.07$ & $1.45 \pm 0.06$ & $1.45 \pm 0.06$ \\
\hline Medium (n=312) & $1.39 \pm 1.01$ & $1.37 \pm 0.06$ & $1.38 \pm 0.05$ & $1.38 \pm 0.05$ \\
\hline High $(n=59)$ & $1.46 \pm 1.22$ & $1.44 \pm 0.14$ & $1.42 \pm 0.13$ & $1.42 \pm 0.13$ \\
\hline$p$ Value & 0.853 & 0.625 & 0.733 & 0.714 \\
\hline \multicolumn{5}{|l|}{ Age at first birth } \\
\hline \multicolumn{5}{|l|}{ Smoking status } \\
\hline Never $(n=1294)$ & $26.9 \pm 5.2$ & $27.0 \pm 0.1^{*} \dagger$ & $27.0 \pm 0.1^{*} \dagger$ & $27.0 \pm 0.1^{*} \dagger$ \\
\hline Former $(n=728)$ & $27.4 \pm 5.4$ & $27.2 \pm 0.2 \dagger$ & $27.3 \pm 0.2 \dagger$ & $27.2 \pm 0.2^{*}$ \\
\hline Current $(n=640)$ & $26.7 \pm 5.2$ & $26.6 \pm 0.2^{\star}$ & $26.6 \pm 0.2^{*}$ & $26.6 \pm 0.2 \dagger$ \\
\hline p Value & 0.016 & 0.035 & 0.051 & 0.047 \\
\hline \multicolumn{5}{|l|}{ HSI categories } \\
\hline Low $(n=178)$ & $27.4 \pm 5.1^{*}$ & $27.1 \pm 0.4^{*}$ & $27.0 \pm 0.4^{*}$ & $27.0 \pm 0.4^{*}$ \\
\hline Medium $(n=236)$ & $26.7 \pm 5.3^{\star} \dagger$ & $26.8 \pm 0.3^{*}$ & $26.9 \pm 0.3^{*}$ & $26.9 \pm 0.3^{*}$ \\
\hline High $(n=41)$ & $24.6 \pm 4.6 \dagger$ & $24.4 \pm 0.8 \dagger$ & $24.5 \pm 0.8 \dagger$ & $24.5 \pm 0.8 \dagger$ \\
\hline p Value & 0.009 & 0.014 & 0.020 & 0.016 \\
\hline \multicolumn{5}{|c|}{$\begin{array}{l}\text { Results are expressed as mean } \pm \text { SD or as adjusted mean } \pm \text { SE. Between group comparisons by analysis of variance. Model } 1 \text {, unadjusted; } \\
\text { model 2, adjusted for age, body mass index, Caucasian status (yes/no), alcohol consumption (four groups), caffeinated drinks consumption } \\
\text { (four groups), educational level (three groups) and receiving social help (yes/no); model } 3 \text {, same as model } 2 \text { plus diabetes (yes/no), current } \\
\text { contraception (yes/no), marital status, retinoic acid and anticancer drugs; model } 4 \text {, same as } 3 \text { plus ever used contraception (yes/no). Post-hoc } \\
\text { bivariate analyses by the Scheffe's method; Groups with different superscript signs " and †' are significantly different at p<0.05. } \\
\text { HSI, Heaviness of Smoking Index. }\end{array}$} \\
\hline
\end{tabular}

between HSI and younger age at menopause was found (see online supplementary table S3).

The impact of smoking on incidence of menopause was assessed by restricting the analyses to 1257 nonmenopausal women at baseline and assessing the age of cessation of menses. Their mean $( \pm \mathrm{SD})$ age was $43.6 \pm 5.3$ and $49.4 \pm 5.4$ at baseline and follow-up, respectively; median follow-up time was 5.3 years and 118 (9.4\%) reported having a hysterectomy with ovariectomy. After adjusting for age, BMI, alcohol consumption (four groups), caffeinated drinks consumption (four groups), educational level (three groups), receiving social help (yes/no), diabetes (yes/no), retinoic acid and anticancer drugs (yes/no), women who smoked at baseline had a HR of 1.34 (1.04 to 1.72 ), $\mathrm{p}<0.05$ of reaching menopause relative to women who did not smoke at baseline; the corresponding value for former women smokers at baseline was 0.96 ( 0.75 to 1.24$), p=0.78$. No violation of the assumption of proportional hazards was found for smoking categories $(p=0.104)$. Restricting the analysis to incidence of non-surgically induced menopause (ie, excluding women who reported having a hysterectomy with ovariectomy) led to similar findings: women who smoked at baseline had a HR of 1.41 (1.08 to 1.86), $\mathrm{p}=0.013$ of reaching menopause relative to women who did not smoke at baseline; the corresponding value for former women smokers at baseline was 0.98 (0.74 to 1.30), $\mathrm{p}=0.91$. Among smokers, a borderline significant association was found between HSI and the risk of reaching menopause: HR 1.06 (0.999 to 1.12 ), $\mathrm{p}=0.052$ for one unit increase in HSI, but the assumption of proportional hazards was not met $(p=0.002)$. Restricting the analysis to incidence of non-surgically induced menopause led to non-significant findings, that is, the HR of reaching menopause for one unit increase in HSI was 1.09 (0.93 to 1.28$), \mathrm{p}=0.289$.

\section{DISCUSSION}

This study assessed the impact of smoking on the number of children and age at menopause using a population-based setting. Many studies have investigated fertility and smoking in the setting of medically assisted procreation. But this subpopulation was clearly different of the general population, as it has sought medical assistance, because of an initial fertility problem. Conclusion on this subpopulation could not be extrapolated in the general population, and this could explain the difference between our results and the previous findings. Our results confirm the deleterious effect of smoking among women on the number of children and in accelerating the occurrence of menopause. Conversely, no consistent dose-effect relationship between heaviness of smoking (as assessed by HSI) and the number of children was found. 
Smoking and number of children, men

Smoking has been shown to alter the quantity and the quality of spermatozoids. ${ }^{12-14}{ }^{19}$ Conversely, the effects of smoking on fertility among men have seldom been assessed and the results are conflicting. In this study, after multivariate adjustment, no association was found between smoking status or HSI categories among smokers and the number of children or age at first childbirth. Our findings are in agreement with those of Bolumar et $a l^{20}{ }^{20}$ who found no difference in fertility between male smokers and non-smokers and with a study conducted among infertile men that found no association between sperm parameters and intensity of smoking. ${ }^{21}$ Conversely, studies conducted in India ${ }^{14}$ and Jordan $^{22}$ reported significantly lower sperm motility and increased sperm morphological defects among smokers. Possible explanations rely on the amount and type of tobacco smoked, which could differentially impact spermatogenesis, but more studies are needed to confirm this hypothesis.

Overall, our results suggest that in our sample, neither smoking nor smoking intensity appear to influence male fertility, but it would be of interest that these findings be replicated in other cohorts. Still, male smokers should be counselled to stop, as smoking has been shown to alter DNA and microRNA expression in spermatozoa, ${ }^{23} 24$ with potential genetic and epigenetic consequences in offspring. ${ }^{25}$

\section{Smoking and number of children, women}

Female smokers reported a lesser number of children than former and never smokers, when adjusted for age, BMI, Caucasian status, alcohol consumption, caffeinated drinks consumption, educational level and receiving social help, while no differences were found when adjusting in addition for diabetes, current contraception, marital status, retinoic acid and anticancer drugs, and with ever used contraception. There was no statistically significant difference between HSI groups among current smokers. The difference, statistically significant, was relatively small $(1.41,1.47$ and 1.56 child per participant, for smokers, former smokers and never smokers, respectively). Nevertheless, at a population scale, this could lead to important differences. These findings are in agreement with a previous study by Ausgood et $a l^{4}{ }^{4}$ who showed that female smokers were more frequently infertile than non-smokers. Another hypothesis would be that smokers tend to have children who will smoke in the next generation, as stated by Chassin et al. ${ }^{26}$ And exposure to smoke during the fetal life was correlated to infertility decades after. ${ }^{7}$

Besides reduced fertility and increased number of complications during pregnancy among smokers, ${ }^{5}$ several other explanations can be put forward to explain the lesser number of children among women who smoke. For instance, smoking status is usually related to a lower socioeconomic status ${ }^{27}$ and thus to a lower economic capacity to care for several children. Although adjustments for education and social help were performed, it is possible that some residual confounding persisted and that the impact of socioeconomic status related to cigarette smoking was not fully accounted for. Conversely, the absence of association between HSI and the number of children among smokers does not confirm previous findings of Bolumar et $a l^{20}{ }^{20}$ who reported that smoking exerts a dose-dependent effect on decreased fertility.

Contrary to Hull et $a l^{15}$ no association was found between active smoking and delayed conception; rather, female smokers reported a younger age at first birth than former or never smokers. The most likely explanation is differences in socioeconomic status. Indeed, in Switzerland, smoking is more prevalent among lower educated persons ${ }^{27}{ }^{28}$ while educational level is positively associated with age at firth birth in both genders. ${ }^{29}$ Balbo $e t a l^{30}$ analysed the role of education on the postponement of childbearing; education was associated with an older age at birth of the first child, but not with the number of children, a finding also reported by others. ${ }^{31}$

Overall, our results indicate that smoking is associated with a lower age at first birth in women, although a possible residual confounding by socioeconomic factors cannot be ruled out. Conversely, no association was found between HSI and the number of children or age at first birth.

\section{Smoking and age at menarche/menopause}

In women, no differences were found regarding age at menarche between smoking status or HSI categories. Conversely, menopause occurred more than a year sooner for current smokers compared with never smokers, while former smokers showed values between never and current smokers. This finding is in accordance with a recent meta-analysis ${ }^{11}$ and could be one of the reasons of decreased fertility in women. Further, the association between age and menopause and smoking seemed to be dose-dependent, with a borderline significant HR of 1.06 (0.999 to 1.12), a finding also by Dechanet $e t a l^{5}$ The lack of significance in our study is likely due to the small sample size; it would be of interest to replicate our findings in other cohorts.

\section{Strengths and limitations}

This study has several strengths. It is population-based, collected data on large number of participants and allowed adjusting for a number of possible confounding variables known to influence fertility, such as alcohol and caffeine intake, ${ }^{32}$ certain drugs or BMI. ${ }^{33}$

This study also has several limitations worth acknowledging. First, no data was available regarding the number of pack-years smoked and the exposure to secondhand smoking; thus, it was not possible to correlate the total amount of tobacco smoked with the number of children or age at first birth. Still, the use of HSI enabled to test a dose-effect association between 
smoking and the outcomes of interest. It is noteworthy that it was only self-reported data, and the magnitude of smoking could be underestimated or minimised. The smoking status was assessed at the time of examination, independently of the family planning schedule, meaning that we could lose some information (eg, having quit smoking at the time of examination, and relapsing just after). Second, no information regarding time after quitting was available for former smokers, and it has been suggested that both women's fertility ${ }^{34}$ and men's sperm quality increase after quitting smoking. ${ }^{35}$ Still, the strength of the associations observed for former smokers was consistent between those observed for never and current smokers, suggesting a reversal of the deleterious effects of smoking after quitting. Third, no data was collected regarding the willingness to have children or the number of pregnancies (including stillborn, voluntary abortions or miscarriages, and complications), and it has been shown that smoking increases the likelihood of non-successful pregnancies. ${ }^{36}$ Thus, it is possible that the magnitude of the negative association between smoking and fertility be overestimated. Still, the negative association between smoking and the number of live children has been reported by others. ${ }^{45}$ No information was available regarding adopted children. Hence, it is likely that some participants included adopted children in their responses. This would lead to an overestimation of the number of natural children, but we had no way of sorting this out. This also applied for children from reconstituted families. Fourth, only a limited number of socioeconomic status parameters were available, and possible residual confounding cannot be ruled out. Still, we used the most common marker of socioeconomic status (educational level) together with a marker of economic deprivation (receiving social help), hence the residual effect of other socioeconomic conditions might not be of importance. Fifth, no data on secondhand smoking was available in our study, despite the fact that it has been shown to influence fertility. ${ }^{37}$ Separate analyses were conducted for women and men as a significant $(p=0.001)$ interaction was found between gender and smoking status regarding the number of children and age at first birth, and also because it would have been difficult to justify an adjustment on contraception in men. Still, we conducted a joint analysis in men and women, the results of which are summarised in online supplementary table S4; the results were comparable to those reported separately for each gender, that is, no association with the number of children but lower age at first birth among current smokers. Sixth, it was not possible to confirm whether the hysterectomies performed were truly with ovariectomy or not, and the date of the intervention. Still, the results obtained after restricting the analyses to women without hysterectomy were comparable to the ones obtained using the whole sample. The fact that some results were non-significant could be due to the smaller sample size and lower statistical power. Finally, no data regarding the smoking status of the parents was available, and as it was shown, the fertility of the offspring was reduced by smoking parents. ${ }^{38-40}$

\section{CONCLUSION}

Smoking is associated with a younger age at first birth and at menopause among women. No association was found in men. No dose-dependent association of smoking on the number of children or on the age at first birth was observed.

Acknowledgements The authors thank Dr Julien Vaucher, Department of Internal Medicine, University of Lausanne, Switzerland for contributing to data acquisition. They are grateful to the research nurses responsible for the recruitment of participants and collection of data, and finally to all participants of the CoLaus Study.

Contributors J-BO wrote most of the article. PM-V helped in the statistical analysis and in the writing of the article. PM-V, FB, PV and GW collected data and wrote part of the article. PM-V had full access to the data and is the guarantor of the study.

Funding The CoLaus study was and is supported by research grants from GlaxoSmithKline, the Faculty of Biology and Medicine of Lausanne, and the Swiss National Science Foundation (grant numbers 33CSCO-122661, 33CS30-139468 and 33CS30-148401)

Disclaimer None of the funders had any role in the study design, the analysis or interpretation of the data, in the writing or in the decision to submit the manuscript.

\section{Competing interests None declared.}

Ethics approval The CoLaus study has been approved by the Institutional Ethics Committee of the University of Lausanne.

Provenance and peer review Not commissioned; externally peer reviewed.

Data sharing statement No additional data are available.

Open Access This is an Open Access article distributed in accordance with the Creative Commons Attribution Non Commercial (CC BY-NC 4.0) license, which permits others to distribute, remix, adapt, build upon this work noncommercially, and license their derivative works on different terms, provided the original work is properly cited and the use is non-commercial. See: http:// creativecommons.org/licenses/by-nc/4.0/

\section{REFERENCES}

1. Aitken RJ. Age, the environment and our reproductive future: bonking baby boomers and the future of sex. Reprod Camb Eng 2014;147:S1-11.

2. Sharma R, Biedenharn KR, Fedor JM, et al. Lifestyle factors and reproductive health: taking control of your fertility. Reprod Biol Endocrinol 2013;11:66.

3. Alvarez S, Devouche E. [First French national survey on lifestyle and toxic factors in infertile couples]. Gynécol Obstét Fertil 2012;40:765-71.

4. Augood C, Duckitt K, Templeton AA. Smoking and female infertility: a systematic review and meta-analysis. Hum Reprod Oxf Engl 1998;13:1532-9.

5. Dechanet C, Anahory T, Mathieu Daude JC, et al. Effects of cigarette smoking on reproduction. Hum Reprod Update 2011;17:76-95.

6. Benedict MD, Missmer SA, Vahratian A, et al. Secondhand tobacco smoke exposure is associated with increased risk of failed implantation and reduced IVF success. Hum Reprod Oxf Engl 2011;26:2525-31.

7. Anderson RA, Mcllwain L, Coutts $S$, et al. Activation of the aryl hydrocarbon receptor by a component of cigarette smoke reduces germ cell proliferation in the human fetal ovary. Mol Hum Reprod 2014;20:42-8.

8. Kaufman DW, Slone D, Rosenberg L, et al. Cigarette smoking and age at natural menopause. Am J Public Health 1980;70:420-2. 
9. Morris $\mathrm{DH}$, Jones ME, Schoemaker MJ, et al. Body mass index, exercise, and other lifestyle factors in relation to age at natural menopause: analyses from the breakthrough generations study. Am J Epidemiol 2012;175:998-1005.

10. DeLellis Henderson K, Bernstein L, Henderson B, et al. Predictors of the timing of natural menopause in the Multiethnic Cohort Study. Am J Epidemiol 2008:167:1287-94.

11. Schoenaker DA, Jackson CA, Rowlands JV, et al. Socioeconomic position, lifestyle factors and age at natural menopause; a systematic review and meta-analyses of studies across six continents. Int J Epidemiol 2014;43:1542-62.

12. $\mathrm{Li} \mathrm{Y}$, Lin $\mathrm{H}$, Li Y, et al. Association between socio-psycho-behavioral factors and male semen quality: systematic review and meta-analyses. Fertil Steril 2011;95:116-23.

13. Calogero A, Polosa R, Perdichizzi A, et al. Cigarette smoke extract immobilizes human spermatozoa and induces sperm apoptosis. Reprod Biomed Online 2009;19:564-71.

14. Mitra A, Chakraborty B, Mukhopadhay D, et al. Effect of smoking on semen quality, $\mathrm{FSH}$, testosterone level, and CAG repeat length in androgen receptor gene of infertile men in an Indian city. Syst Biol Reprod Med 2012;58:255-62.

15. Hull MG, North K, Taylor H, et al. Delayed conception and active and passive smoking. The Avon Longitudinal Study of Pregnancy and Childhood study team. Fertil Steril 2000;74:725-33.

16. Firmann M, Mayor V, Vidal PM, et al. The CoLaus study: a population-based study to investigate the epidemiology and genetic determinants of cardiovascular risk factors and metabolic syndrome. BMC Cardiovasc Disord 2008;8:6.

17. Section de Santé Office Fédéral de la Statistique: Enquête Suisse sur la Santé 2007. Les indices. [Swiss Health Survey 2007. Indexes]. Neuchâtel, Switzerland: Office fédéral de la statistique, 2008.

18. Heatherton TF, Kozlowski LT, Frecker RC, et al. Measuring the heaviness of smoking: using self-reported time to first cigarette of the day and number of cigarettes smoked per day. Br J Addict 1989;84:791-9.

19. Swan SH, Elkin EP, Fenster L. The question of declining sperm density revisited: an analysis of 101 studies published 1934-1996. Environ Health Perspect 2000;108:961-6.

20. Bolumar F, Olsen J, Boldsen J. Smoking reduces fecundity: a European multicenter study on infertility and subfecundity. The European Study Group on Infertility and Subfecundity. Am J Epidemiol 1996;143:578-87.

21. Caserta D, Bordi G, Di Segni N, et al. The influence of cigarette smoking on a population of infertile men and women. Arch Gynecol Obstet 2013;287:813-18.

22. Al-Matubsi HY, Kanaan RA, Hamdan F, et al. Smoking practices in Jordanian people and their impact on semen quality and hormonal levels among adult men. Cent Eur J Public Health 2011;19:54-9.

23. Perrin J, Tassistro V, Mandon M, et al. Tobacco consumption and benzo(a)pyrene-diol-epoxide-DNA adducts in spermatozoa: in smokers, swim-up procedure selects spermatozoa with decreased DNA damage. Fertil Steril 2011;95:2013-17.
24. Marczylo EL, Amoako AA, Konje JC, et al. Smoking induces differential miRNA expression in human spermatozoa: a potential transgenerational epigenetic concern? Epigenetics 2012;7:432-9.

25. Laubenthal J, Zlobinskaya O, Poterlowicz K, et al. Cigarette smoke-induced transgenerational alterations in genome stability in cord blood of human F1 offspring. FASEB J 2012;26:3946-56.

26. Chassin L, Presson CC, Rose J, et al. Parenting style and smoking-specific parenting practices as predictors of adolescent smoking onset. J Pediatr Psychol 2005;30:333-44.

27. Stringhini S, Spencer B, Marques-Vidal P, et al. Age and gender differences in the social patterning of cardiovascular risk factors in Switzerland: the CoLaus study. PLoS ONE 2012;7:e49443.

28. Gmel G, Kuendig H, Notari L, et al. Monitorage suisse des addictions-Consommation d'alcool, tabac et drogues illégales en Suisse en 2012. Addiction Suisse, Lausanne, Suisse, 2013. http:// www.suchtmonitoring.ch/docs/library/gmel_kk9q81afisp0.pdf.

29. Wanner P, Fei P. Facteurs influencant le comportement reproductif des Suissesses et des Suisses. Neuchatel: Office fédéral de la statistique, 2005.

30. Balbo N, Billari FC, Mills M. Fertility in advanced societies: a review of research: La fécondité dans les sociétés avancées: un examen des recherches. Eur J Popul Rev Eur Demogr 2013;29:1-38.

31. Skirbekk V. Fertility trends by social status. Demogr Res 2008;18:145-80.

32. Hakim RB, Gray RH, Zacur H. Alcohol and caffeine consumption and decreased fertility. Fertil Steril 1998;70:632-7.

33. Jacobsen BK, Knutsen SF, Oda K, et al. Body mass index at age 20 and subsequent childbearing: the Adventist Health Study-2. $J$ Womens Health 2002 2013;22:460-6.

34. de Ziegler D, Santulli P, Seroka A, et al. In women, the reproductive harm of toxins such as tobacco smoke is reversible in 6 months: basis for the "olive tree" hypothesis. Fertil Steril 2013;100:927-8.

35. Santos EP, López-Costa S, Chenlo P, et al. Impact of spontaneous smoking cessation on sperm quality: case report. Andrologia 2011;43:431-5.

36. Hure AJ, Powers JR, Mishra GD, et al. Miscarriage, preterm delivery, and stillbirth: large variations in rates within a cohort of Australian women. PLoS ONE 2012;7:e37109.

37. Hyland A, Piazza K, Hovey KM, et al. Associations between lifetime tobacco exposure with infertility and age at natural menopause: the Women's Health Initiative Observational Study. Tob Control 2015;0:1-9.

38. Jensen TK, Joffe M, Scheike T, et al. Early exposure to smoking and future fecundity among Danish twins. Int J Androl 2006;29:603-13.

39. Weinberg CR, Wilcox AJ, Baird DD. Reduced fecundability in women with prenatal exposure to cigarette smoking. Am J Epidemiol 1989;129:1072-8.

40. Jensen TK, Jørgensen N, Punab M, et al. Association of in utero exposure to maternal smoking with reduced semen quality and testis size in adulthood: a cross-sectional study of 1,770 young men from the general population in five European countries. Am J Epidemiol 2004;159:49-58. 